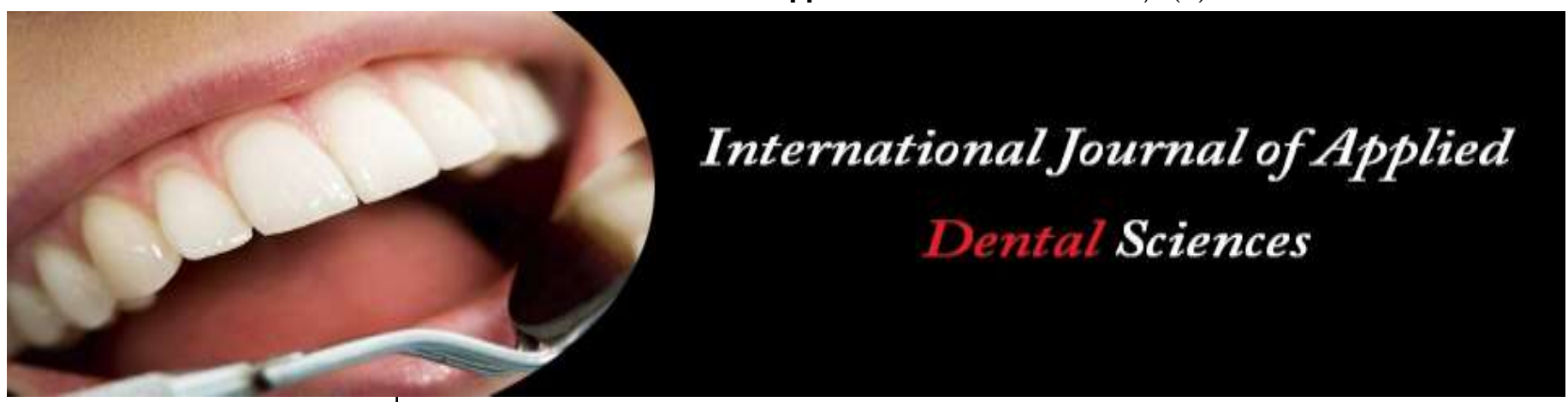

ISSN Print: 2394-7489

ISSN Online: 2394-7497

IJADS 2020; 6(4): 430-434

(C) 2020 IJADS

www.oraljournal.com

Received: 16-08-2020

Accepted: 03-10-2020

\section{Reem Nsaif}

Ph. D Student, Department of Prosthodontics, Faculty of Dentistry, Atatürk University, Erzurum, Turkey

Funda Bayindir

Ph. D, Department of

Prosthodontics, Faculty of

Dentistry, Atatürk University,

Erzurum, Turkey
Corresponding Author: Reem Nsaif

Ph. D Student, Department of Prosthodontics, Faculty of Dentistry, Atatürk University, Erzurum, Turkey

\section{How can digital dentistry affect geriatric patient's treatment?}

\section{Reem Nsaif and Funda Bayindir}

DOI: https://doi.org/10.22271/oral.2020.v6.i4g.1097

\section{Abstract}

With the developing technologies in recent years, digital dentistry has become quite common. While both conventional techniques and digital dentistry have their own benefits and limitations, still digital technology is superior and going toward future for all specialties in health care field and consequently for elderly patient's treatment. Content of dental researches, web researches, on-line data bases, discussions of experts and clinicians with the most recent publications and new products releases were collected and evaluated. With rapid aging, the measures surrounding oral health care in the elderly have significantly improved by digital dentistry that bringing new technique system to give opportunity for improving health of geriatric patients as well as opening a new field for future researches. Digital dentistry has an abundance of positive outcomes that make dental treatment for geriatric patients easier, and more efficient.

Keywords: Geriatric dentistry, digital dentistry, CAD CAM, aging

\section{Introduction}

In recent decades it was noticed that an accelerated increase in the length of human life in developing countries, in the latest stats for 2019 there were 703 million persons aged 65 years or more in the world and this number can duplicate to reach about 1.5 billion in 2050 (Fig.1), and this varied increase, will represent a significant challenges for health care providers, and many social care programs ${ }^{[1-5]}$.

There are several main restricting causes that affecting continuous submitting dental care program: ${ }^{[2]}$.

1. The distance of the clinic and ease of access to.

2. Time effect (suitable time for each patient)

3. Equipment is not enough

4. No financial support

5 . Number of workers is not sufficient.

6. Inadequate training and experience of the dental team

7. There is no planning and communion between work entities.

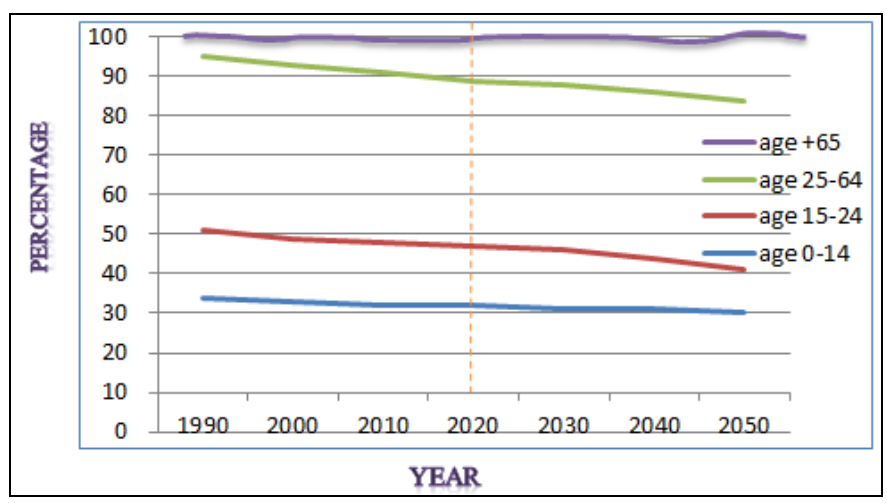

Fig 1: World population by age groups ranging from $\left(0-{ }^{+} 65\right)$ 1990-2050 $\sim 430 \sim$ 
It is essential for dentists to receive necessary knowledge to prevent and treat oral diseases for this group of people. The topic of gerontology has just become a theoretical unit which has been added to the dental curriculum in Dentistry Colleges in all over the world and in that direction those colleges are planning educational programs. On the other hand, with the development of information technology, medical education methods have been transformed and currently use of newer methods such as virtual tutorials are being stressed for knowledge application. ${ }^{[6-8]}$

\section{Origin of Digital Dentistry}

Digital dentistry is in itself not a new concept, as computeraided design and computer-aided manufacturing (CAD/CAM) was invented in 1973 and implemented for practice during the 1980s in more regular way. While there is no doubt that dental CAD/CAM revolutionized dentistry, it was in its early stages considered to be some kind of impractical modernity, as it required more time to produce a viable product due to slow speeds and a heavy mediator. ${ }^{[9-11]}$

Dental CAD/CAM systems have showed rapid development, and nowadays 3D model scanners and dental CAD/ CAM systems are used all over world. Today there are a many different dental chair side and laboratory-based CAD/CAM systems, such as Procera (Nobel Biocare), Lava (3M ESPE), Cercon (DENTSPLY Ceram-co), CEREC (Sirona), and E4D (D4D Technologies), as example names. These systems are used to design and manufacture metal, alumina, and zirconia frameworks, as well as all-ceramic and composite full-contour crowns, inlays, and veneers ${ }^{[9,12]}$

Table 1: Obstacles and motivations to adoption of digital technology [11]

\begin{tabular}{|c|c|c|c|c|c|}
\hline \multicolumn{6}{|c|}{ Obstacles and motivations to adoption of digital technology } \\
\hline & Pragmatic & $\begin{array}{l}\text { Education } \\
\end{array}$ & \begin{tabular}{|c|} 
User \\
\end{tabular} & Clinical Environment & Social Environment \\
\hline Obstacles & $\begin{array}{l}\text { - Cost } \\
\text { - Learning curve } \\
\text { - Complecations } \\
\text { - Related Capital } \\
\text { investment (space, IT } \\
\text { support) } \\
\end{array}$ & $\begin{array}{l}\text { - Access to new information } \\
\text { - Pragmatic barriers } \\
\text { imposed at dental schools } \\
\text { - No CODA standards } \\
\text { driving option }\end{array}$ & $\begin{array}{l}- \text { Lack of basic dc } \\
\text { dexterity } \\
\text { - Lack of access to new } \\
\text { information } \bullet \text { digging } \\
\text { - Fear }\end{array}$ & $\begin{array}{l}\text { - Lack of peer support } \\
\text { - Absence of IT } \\
\text { knowledge or support } \\
\text { - Absence of dental } \\
\text { laboratory support }\end{array}$ & $\begin{array}{l}\text { Absence of buildup } \\
\text { education in } \\
\text { community } \\
\text { - Lack of upholding } \\
\text { from local laboratories } \\
\text { - Little industry support }\end{array}$ \\
\hline $\begin{array}{c}\text { Motivations\& } \\
\text { Advantages }\end{array}$ & $\begin{array}{l}\text { - Cost savings } \\
\text { - Space savings } \\
\text { - Quality } \\
\text { - Predictability and } \\
\text { standardization } \\
\text { communication } \\
\text { - Archived storage }\end{array}$ & $\begin{array}{l}\text { - Pragmatic advantages } \\
\text { provided to dental schools } \\
\text { - Industry supports } \\
\text { education } \bullet \text { For profit } \\
\text { educational opportunities }\end{array}$ & $\begin{array}{l}\text { - Advantage in } \\
\text { marketplace } \\
\text { - Workplace enforced } \\
\text { - Laboratory } \\
\text { encouragement } \\
\text { - Recognition of } \\
\text { pragmatic incentives and } \\
\text { barriers }\end{array}$ & $\begin{array}{l}\text { - IT support } \\
\text { - Digital environment in } \\
\text { place } \\
\text { - Multi-doctor } \\
\text { workplace } \\
\text { - Educational support in } \\
\text { house (peers) } \\
\text { - Frequent need and use }\end{array}$ & $\begin{array}{l}\text { - local dental } \\
\text { organizations support } \\
\text { - Local key opinion } \\
\text { leader influence } \\
\cdot \text { support from Local } \\
\text { laboratory }\end{array}$ \\
\hline
\end{tabular}

Beginning the process with a physical starting point, such as a patient or cast model, an intraoral scanner is used to collect information and form a digital replica, which is stored as a file. In the second step, the information is formatted in such a way that CAD/CAM software is able to display the information and permit modifications. Once the changes have been made to the digital model, it is ready for the final step of $3 \mathrm{D}$ printing, or milling, where it becomes a physical reproduction of the digital information and, 9,13 this is a general figure for the entire method that more detailed explanations will mentioned in order later.

\section{Dental Care for Geriatric Pateints}

With the advances in different medical fields, good education and healthy nutrition and making working conditions more beneficent all these factors increasingly improve duration of fourth age and will reduce risk factors for them. ${ }^{[11,12]}$

Despite of progression and success in preventive and oral care dentistry and with the gradual and remarkable raising in the number of persons who fellow these developments still elderly patients show negatively and slowly response to this health care at age between 60 and 65. ${ }^{[13,14]}$ The risk of medical problems (multi morbidity, poly pharmacy), which increase with age, play a major role in pulling back from care with major outcomes for dental and oral health in the long term. Confrontation these complex challenges, for dentists it is important to learn how to deal with all these difficulties to make treatment easier, more effective and persuasively attract elderly category to come to the clinic and even they will enjoy receiving such a care type. ${ }^{[11,15]}$

\section{Digital opportunities}

Those who are handling digital community are capable of generate rapidly growing data every day that dental care specialist can use it inmost and more functional prudence into the lifestyle of elderly people, for example, by reading and analyzing digital information can allow better understanding for lifestyle, economical, and medical situation of elderly people. This would be one of the many chances to achieve proceed in geriatric dentistry and induce preventive care concept accepted by the patients themselves. ${ }^{[14,16,17]}$ (Fig. 2) 


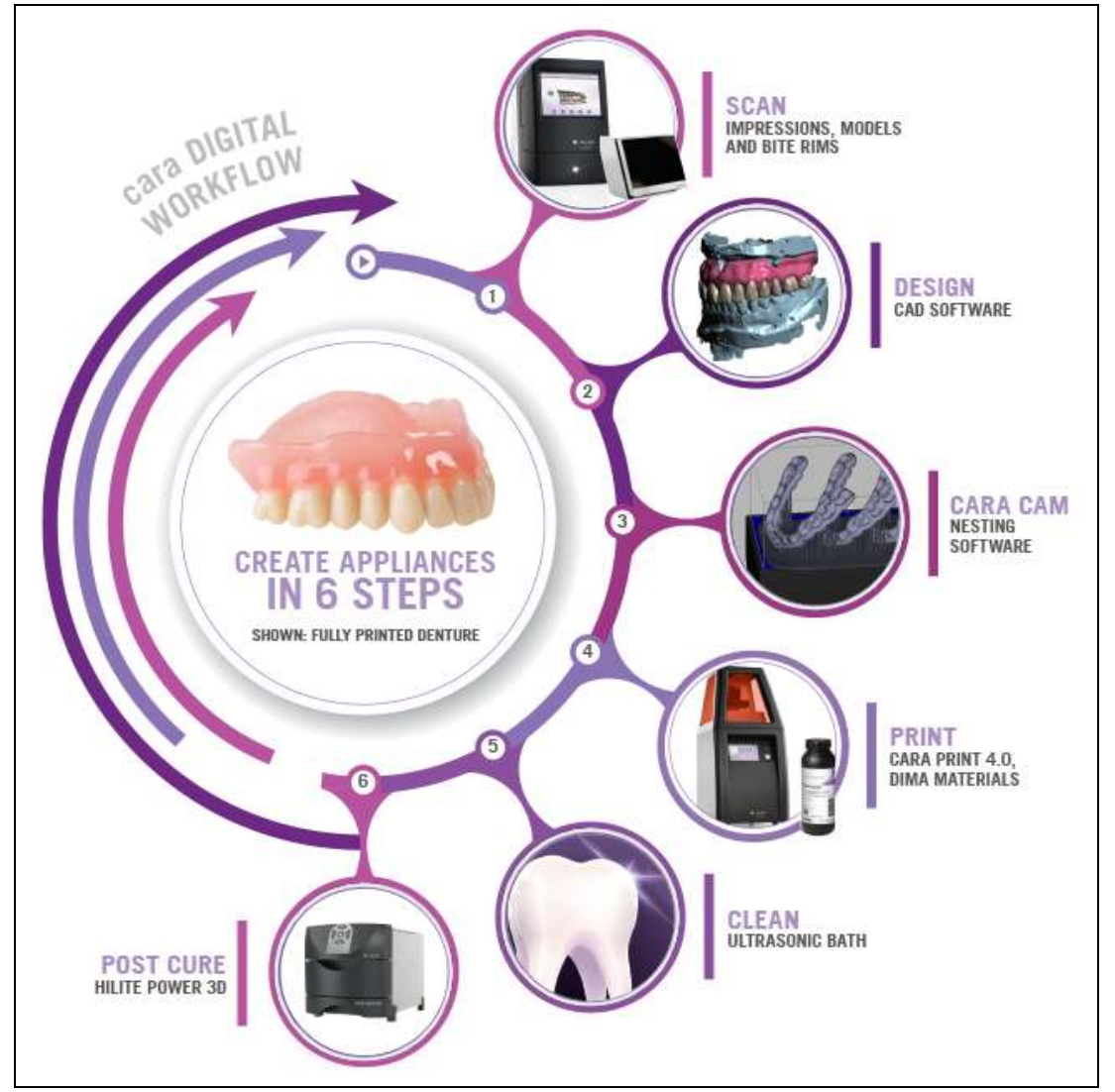

Fig 2: 3D technology for dental appliance

\section{Scanner}

Todays both intra-oral and laboratory-based scanner transformed timed single or multiple teeth dental images, full arches, opposite jaws, occlusion, and surrounding soft tissue. These images explaining treatment opportunity for elderly patients in simple way and they will assess the more restful data process. ${ }^{[18,19]}$ This can save chair time and create a more comfortable experience so patients had not to wait for weeks and make multiple visits to the clinic for dental procedures to be completed which is more exhausted for elderly people. ${ }^{[17}$, 19, 20]

For example, making a classical impression can at times be a boring procedure with the possibility of the patient gagging and misconceptions occurring. If the laboratory needs additional information to be found within the impression, the patient needs to be called back to take the impression which can be hard-pressed. The use of an intraoral scanner can reduce the extent of these issues so more accurate digital impression can be achieved, recovering patient's clinical experience and preferable final prosthetics can produce. ${ }^{[21,22]}$

\section{CAD CAM systems}

The major implications of this technology in dentistry include the ability to make real time modifications in preexisting environments, simulations, documentations of oral landmarks overtime, and a reduction in the number of sessions needed. Although the software portion of digital dentistry has comparatively seen the least amount of advancements in recent years, it has substantially evolved since its conception, bringing its own unique benefits and setbacks. ${ }^{[23,24]}$

Virtual documentation is able to reduce conventional errors and permits easy review without taking up physical storage. The tracking of oral lesions is beneficial to the safety and health of the patient as the examiner can see minuscule changes in size, color, texture, location, and depth and this is an important advantageous for dental care generally and geriatric dentistry specifically ${ }^{[13,25,26]}$.

\section{Digital Impression (Digital Denture)}

Computer-aided design (CAD) and computer-aided manufacturing (CAM) are new technologies that give dental technicians opportunity to make new dentures in a fraction of the time out of material discs. A total prosthesis can be manufactures in just a few procedures.

Advantages to Digital Impressions for elderly patients [21, 27, 28].

\section{Speed and Delicacy}

1. No need to trays with definite dimensions or fabricate customs trays.

2. No need to remake the impressions with immediate scan alteration.

3. Immediate chair side lab communication while the patient is still in the chair.

\section{Patient Experience}

1. Improved treatment and patient relief.

2. No risk of gagging or allergic reaction to impression material.

3. Patient involvement in the treatment steps through chair side visuals.

4. Reducing recalls of prosthesis remake.

\section{Advantages concerning time}

1. Patient case can be started immediately at receiving the scan.

2. Crowns can be fabricated at the same day with in-house grinding so geriatric patient do not have to come for extra visits.

3. Possibilities of voids and bubbles can be removed with 
using of digital scan.

4. Any inaccuracies in digital model, scans can be immediately adjusted in chair side.

\section{Economic aspects}

1. Digital scans remove the possibilities of voids and bubbles which reduce need to crown reinsertion and adjustments.

2. There is no cost of impression materials and trays.

\section{Other dental technologies and innovations}

Other potentially digital applications effect dentistry includes inventions in technology-enabled healthcare and management.

\section{Tele dentistry}

Elderly people find it difficult to visit the dentist for various reasons. Tele dentistry can change all that. Having the means to offer some of your dental services over the internet can help those who don't have easy access to a dentist ${ }^{[17,29]}$.

Tele dentistry can allow your staff and your patients to set appointments online, eliminating the need to wait in line or be put on hold to schedule a consultation. This can also benefit individuals living in rural areas where there's a lack or absence of dental offices. Additionally, this technology will allow patients to consult with you online, and also enable you to create clinical notes that you can send out to other dentists at a click of a button ${ }^{[30-32]}$. It provides easier oncoming oral care, it is greatly cheaper for patients - as in state of costly treatment, and it shifts to cheaper protection trains that permit patients to consult with other else non existing medical professionals ${ }^{[21,30]}$.

\section{Augmented reality}

Augmented reality (AR) will transform the world in every field, especially healthcare believing within a shorter time; augmented reality will up rise dental teaching totally. It is using augmented reality promoting to help dental students all around the world for their skills improvement that it provides not only virtual information, but also to react with the environment that AR feeding employers with a great degree of fluency ${ }^{[28,30]}$, dentists can pursuit complex procedures with minimal costs and no risk to patients, as no material is weed out while during working, making it a cost-efficient solution. ${ }^{[19]}$ Promoting patient information for certain procedures, For example, with AR, rather than taking a cast of the patient's mouth, sending it off to a dental lab, and waiting for it to be processed and sent back, the dentist has the advantage of giving the patient an immediate visual representation of the completed proposed treatment, this may include, crown and bridgework, implants, orthodontics and so on. This manage both time and save patient's money which is important for elderly people as well as the dentist while also the patient will be conformed with a significant sense of what he looks forward ${ }^{[9,28]}$.

\section{Virtual reality}

In dentistry, advantages can be seen mainly by patient experience improving. For example, Virtual reality (VR) can in some cases be used to help handling patient apprehension easily or even offer pain relief; some studies revealed that VR can minimize pain perception. VR thus allows for patients to become deeply involved in an interactive trail, thereby distracting them from the dental procedure. Although VR using more equipment than $\mathrm{AR}$ but with anxiety in the dentist's chair is very familiar; VR might offer a solution! 69 participants in a trail test showed that VR can be used as an effective distraction dental devise ${ }^{[30,34]}$.

\section{Smart toothbrush}

Although it not considered as digital instrument but still one of the recent innovations in dentistry that can help and improve oral health especially for handicapped and geriatric patients. It make tooth brushing much easier for oral hygiene maintenance and plaque prevention or any other oral negative cavities. Smart electric toothbrush makes sure you are brushing your teeth in the right way by its app and exhibit people fun games to motive regular daily good habit of teeth cleaning ${ }^{[21]}$. The toothbrush conjoin a variety of sensors in the handle to register in definite time how you're brushing your teeth. It's pretty simple how it works: as you brush your teeth, a 3D map of your mouth shows you which teeth you're brushing and tells you if you're brushing too much or too little. The app also alarms you if you're scrubbing hardly or using too much pressure ${ }^{[33,34]}$.

\section{Conclussion}

1. Geriatric patients need to be treated as special group of patients with strategic framework for improving oral health.

2. With the development of digital dentistry and dental health innovations; old age patients had to receive should receive advanced, more accurate and less timeconsuming methods of treatment and dental care, taking into account their health and psychological state.

3. Educate elderly patients about digital dentistry, its importance and positive aspects in treatment, the accuracy of results, time acquisition and ease of use.

Digital technology has showed a lot of advantages to geriatric dentistry while these usefulness are predominantly notable and clearly paramount digital from conventional techniques, in all digital dental implementations from electronic records of patients to eclectic laser felting of difficult prosthetic systems, the mainly benefits of greater quality, improved communication, data archiving, increased control, and, patient practicing betterment is simply cannot be resembled using present traditional methods mentioned and make comparing that include charge, delicacy or usefulness, and consequences. Medical and dental healthcare suppliers should confirm an interdisciplinary rapprochement by activating these digital systems for clinical practice routinely. Smart digital applications are necessary, that enable, rapid, harmonious and safe interdisciplinary reciprocation for data on a patient-bypatient level to individually back up proportional decisionmaking that depend on how much there is a recognition for all stakeholders concerning old age patients in-home and out-ofhome care regulations. Transforming to digital techniques give the chance to obtain a pattern shift in geriatric dentistry and preventive elevation rather than soothing healthcare estimations.

\section{References}

1. Núñez, María del Rosario Ruiz, Martini, Jussara Gue, Siedler, Mônica Joesting, Mello, Ana Lúcia Schaefer Ferreira de. Geriatric dentistry teaching and the curricular guidelines in dental schools in South American countries. Revista Brasileira de Geriatria e Gerontologia. 2017;20(6):826-835.

2. Jongen $\mathrm{W}$. The impact of the long-term care reform in the Netherlands: an accompanying analysis of an 'ongoing' 
reform. Published Dissertation 2017.

3. Miura H, Tano R. Recent measures in geriatric oral health care in Japan. J Natl Inst. Public Health. 2019;68(1):8-16.

4. Bandodkar AK, Aras M. Nutrition for geriatric denture patients. J Indian Prosthodont Soc. 2006;6(1):22-28.

5. Administration on Aging (AoA), a Profile of Older Americans: 2015 Administration for Community Living, U.S. Department of Health and Human Services. Website https://aoa.acl.gov/aging_statistics/Profile/2015/docs/201 5-Profile.pdf, Accessed 2/18/2017.

6. World Population Ageing. Highlights. Department of Economic and Social Affairs Population Division. United Nations New York, 2019.

7. Sargeran K, Razeghi S, Khorshidi Z. Design, Implementation, and Assessment of Virtual Training of Dental Students in Elderly Dentistry Topic. Salmand: Iranian Journal of Ageing 2018;13(1):4-15.

8. Zeinalhajlu A, Amini A, Sadeghtabrizi J. Consequences of population aging in Iran with emphasis on its increasing challenges on the health system (Literature review) (Persian)]. Depiction of Health 2015;6(1):54-64.

9. Rekow DE. Digital Dentistry: the new state of the art- is it disruptive or destructive. Journal of Den. Mat. 2020;36:9-24.

10. Larsson A, Sabolová D. Digital dentistry a solution to the dentistry crisis. Chapter. \{online\} Research Gate release: https://www.researchgate.net/publication/336258673, 2020.

11. Lyndon F, Cooper, Mark Ludlow E. The Current Impact of Digital Technology in Prosthodontics. American College of prosthodontists. Digital White Paper, 2017.

12. Grover SS. Geriatric Dentistry: From Entry to Exit and Beyond. Crest Oral-B at dentalcare.com Continuing Education Course, February. \{online\} Research Gate release:

https://www.researchgate.net/publication/293098432, 2016.

13. Zander A, Boniface D. Directly observed daily mouth care provided to care homes residents in one area of Kent, UK, Community Dental Health. 2017;34(1):32-36.

14. Favaretto M, Shaw D, De Clercq E, Joda T, Elger BS. Big Data and Digitalization in Dentistry: A Systematic Review of the Ethical Issues. Int. J. Environ. Res. Public Health. 2020;17:2495.

15. Besimo CE, Zitzmann NU, Joda T. Digital Oral Medicine for the Elderly. Int $\mathbf{J}$ Environ Res Public Health. 2020;17(7):2171.

16. Sulaiman TA. Materials in digital dentistry; A review. J Esthet Restor Dent. 2020;32:171-181.

17. Peffley-Routt T. The Digital World of Dentistry, 2018. https://www.researchgate.net/publication/324603548.

18. Joda T, Waltimo T, Pauli-Magnus C, Probst-Hensch, Zitzmann, NU. Population-Based Linkage of Big Data in Dental Research. Int J Environ Res Public Health. 2018;15:2357-2361.

19. Lehne M, Sass J, Essenwanger A, Schepers J, Thun S. Why digital medicine depends on interoperability. NPJ Digit. Med. 2019;20:79.

20. Joda T, Waltimo T, Probst-Hensch N, Pauli-Magnus C, Zitzmann NU. Health Data in Dentistry: An Attempt to Master the Digital Challenge. Public Health Genomics 2019;22(1-2):1-7.

21. Perry R. Dental technology trends to watch out for in January $3^{\text {rd }}, 2020$ PACT-ONE Solutions, Inc Healthcare,
2020.

22. Planmeca, Planmeca Emerald. Intraoral scanner for brilliant results, https://www.planmeca.com/cadcam/den tal-scanning/planmeca-Emerald/, 2019.

23. Wood B. How Technology Shapes Dentistry's Future. Marley@newcom.ca. Oral Health Group, 2020.

24. Mersel A. An adapted continuing education program in gerodontics: The actual challenge. J Global Oral Health. 2018;1(1):17-20.

25. Lin M, Wang W, Hang J. Digital Solution for the Dental Practice: Making a Lasting "Digital" Impression, 2017.

26. Committee on Pediatric Workforce. The use of telemedicine to address access and physician workforce shortages. Pediatrics. 2015;136(1):202-9.

27. Deferm JT, Schreurs R, Baan F, Bruggink R, Merkx MAW, Xi T et al. Validation of 3D documentation of palatal soft tissue shape, color, and irregularity with intraoral scanning. Clin Oral Investig. 2018;22(3):13031309.

28. Marghalani A, Weber HP, Finkelman M, Kudara Y, El Rafie K, Papaspyridakos P. Digital versus conventional implant impressions for partially edentulous arches: An evaluation of accuracy. J Prosthet Dent. 2018;119(4):574-579.

29. Andriessen FS, Rijkens DR, van der Meer WJ, Wismeijer DW. Applicability and accuracy of an intraoral scanner for scanning multiple implants in edentulous mandibles: A pilot study. J Prosthet Dent. 2014;111:186-194.

30. Joda T, Bornstein MM, Jung, RE, Ferrari M, Waltimo T, Zitzmann NU. Recent Trends and Future Direction of Dental Research in the Digital Era. Int. J. Environ. Res. Public Health. 2020;17:1987.

31. Smith DK, Beaudoin B, Messersmith M, Blume JD. Comparison of Digital Measurement versus Physical Model Measurement: An Analysis of Accuracy and Precision. Dent Health Curr Res. 2017;3:1.

32. Waddell B. The future of dental technology and innovation. ADEA GoDental. Online system service, 2019.

33. Estai M, Bunt S, Kanagasingam Y, Tennant, M. Cost savings from a tele dentistry model for school dental screening: An Australian health system perspective. Aust Health Rev. 2018;42:482-490.

34. Mesko B. The Medical Futurist, Online newsletter, 2016. https://medicalfuturist.com/the-amazing-future-ofdentistry-and-oral-health. 